\title{
Right Testicle Ectopy Associated with Left Renal Agenesis
}

\author{
Mamadou Tidiani Coulibaly, Ousmane Koné, Moumine Zié Diarra, Amadou Berthé, \\ Lahassana Coulibaly, Zanafon Ouattara
}

Urologist at the Gabriel Touré University Hospital Centre, Bamako, Mali

Email: mamadoutc@yahoo.fr

How to cite this paper: Coulibaly, M.T., Koné, O., Diarra, M.Z., Berthé, A., Coulibaly, L. and Ouattara, Z. (2019) Right Testicle Ectopy Associated with Left Renal Agenesis. Surgical Science, 10, 217-221. https://doi.org/10.4236/ss.2019.107023

Received: May 15, 2019

Accepted: July 12, 2019

Published: July 15, 2019

Copyright () 2019 by author(s) and Scientific Research Publishing Inc. This work is licensed under the Creative Commons Attribution-NonCommercial International License (CC BY-NC 4.0).

http://creativecommons.org/licenses/by-nc/4.0/

\begin{abstract}
Testicular ectopia is a rare genital malformation belonging to the spectrum of testicular migration abnormalities. Renal agenesis can be unilateral or bilateral, isolated or associated with other malformations ( $1 / 4$ of renal agenesis is accompanied by genital malformations, and more often affects the left kidney. Few cases are reported in the literature. We report a case in a 28 -year-old patient with ectopia of the right testicle in the suprapubic position associated with agenesis of the left kidney, and surgical management consisted of an orchiectomy, with good surgical results.
\end{abstract}

\section{Keywords}

Testis, Agenesis, Kidney, Migration

\section{Introduction}

Currently, it is accepted that testicular descent takes place under the influence of hormonal and mechanical factors in two phases: transabdominal and transinguinal migration; no position anomalies are possible during this migration [1]. These are mainly cryptorchidism and ectopy. The ectopic testicle defines a testicle outside the purse and the normal migration path. Cryptorchidism is a permanent stop of testicular migration at any point along its normal path between the lumbar region and the scrotum [2].

Ectopy is one of the causes and forms of cryptorchidism (diagnosis of absence of one or two testicles in the bursa, whether due to unfinished testicle migration or total absence) [2].

Renal agenesis can be uni- or bilateral, isolated or associated with other malformations ( $1 / 4$ of renal agenesis is accompanied by genital malformations allowing the anomaly to be dated with respect to embryogenesis) [3]. Unilateral 
agenesis has an incidence of $1 / 1000$, is more frequent in men and affects the left kidney more often [4]. It is often asymptomatic and compatible with life. Compensating hypertrophy is observed in the normal kidney ( $>10 \%$ of normal kidney volume) [5].

\section{Observation}

Mr. Y B, a 28-year-old patient, had consulted for a malposition of the right purse evolving since birth without other associated signs. There is no similar case in siblings. The physical examination revealed a straight ectopic bursa in pubic position containing a testicle of normal size and consistency with normal hair growth (Figure 1).

The left bursa is in a normal anatomical position and contains a testicle of normal size and consistency.

The spermogram showed azoospermia. The uroscanner had objected to agenesis of the left kidney associated with a hypodense mass with some dense iso tissues above the pubis that corresponded to the poorly positioned bursa (Figure 2).

The biological check-up was normal (creatinine, blood sugar, NFS, TP, TS, TCA).

We had decided on a left inguinal orchidectomy. After dissection of the spermatic cord, we proceed to its section and then ligation (Figures 3-5).

\section{Discussion}

Unilateral renal agenesis has an incidence of $1 / 1000$, is more frequent in men and affects the left kidney more often [4]. It is often asymptomatic and compatible with life. Compensating hypertrophy is observed in the normal kidney ( $>10 \%$ of normal kidney volume).

Renal agenesis can be uni- or bilateral, isolated or associated with other malformations (1/4 of renal agenesis is accompanied by genital malformations) [3]. Our patient was elderly, and this delay in care is due to the parents' ignorance.

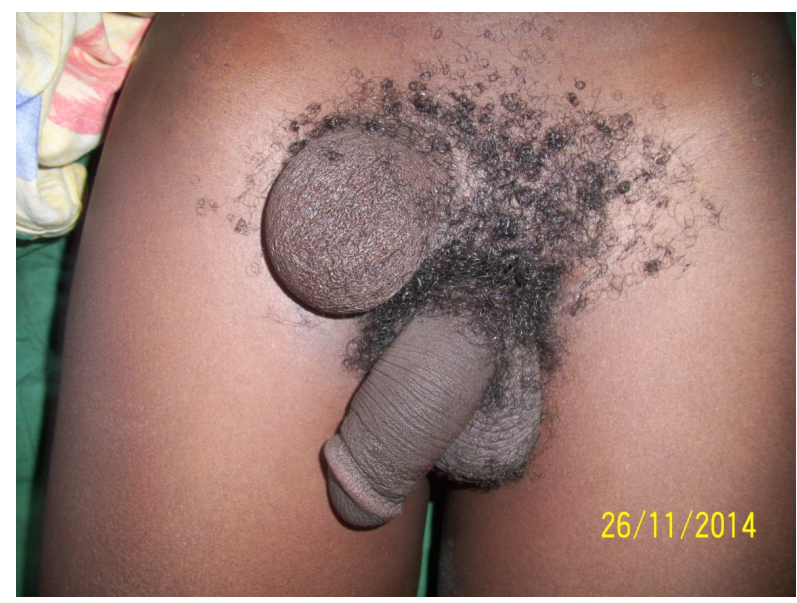

Figure 1. Right testicular ectopy in pubopenial position. 


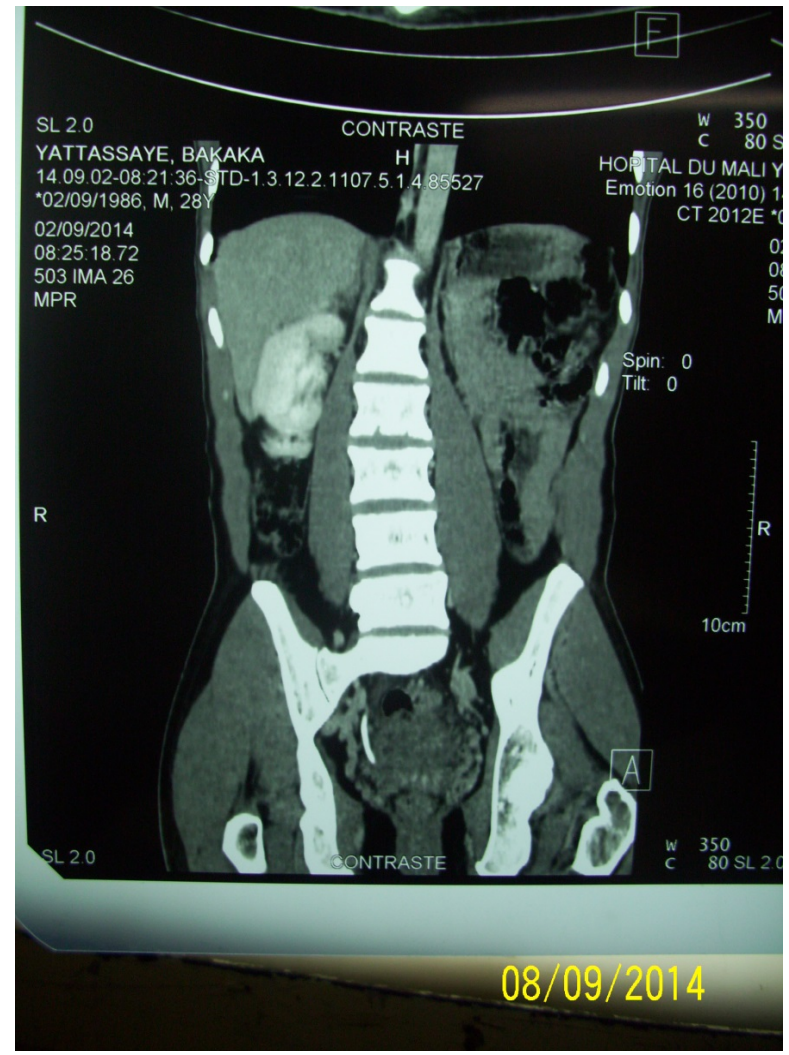

Figure 2. Uro scan ascending an absence of the left kidney.
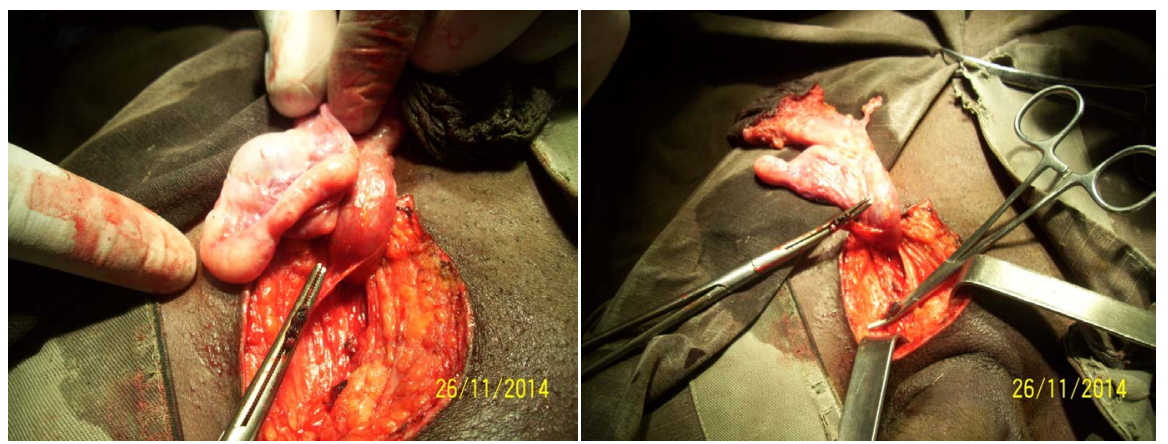

Figure 3. Exhibition of the left testicle.

Several locations have been described, such as interstitial ectopy, the most frequent, pubopenic, femoral, transverse, pelvic and retro-umbilical. In its pubopenial location (in our case), the testicle is located above the penis with the contralateral testicle in normal position. It is a rare congenital anomaly whose etiopathogeny is highly controversial [1]. The role of gubernaculum testis is not clearly understood. Some consider that testicular descent is related to the role of the gubernaculum testis as a tractor and guide, which is controlled by the genito-femoral nerve. Hutson [6] believes that an anomaly in this nerve would cause the migration of gubernaculum testis to an aberrant location. Other authors attribute pubopenial ectopy to the presence of a mechanical obstacle to testicular descent to the bursa, causing the testicle to deviate to areas of lower resistance [7]. 


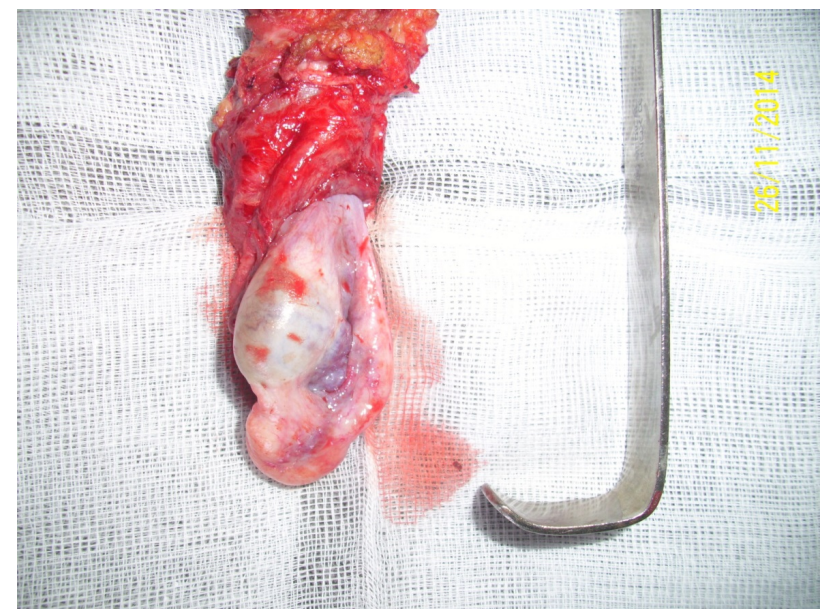

Figure 4. Orchidectomy piece.

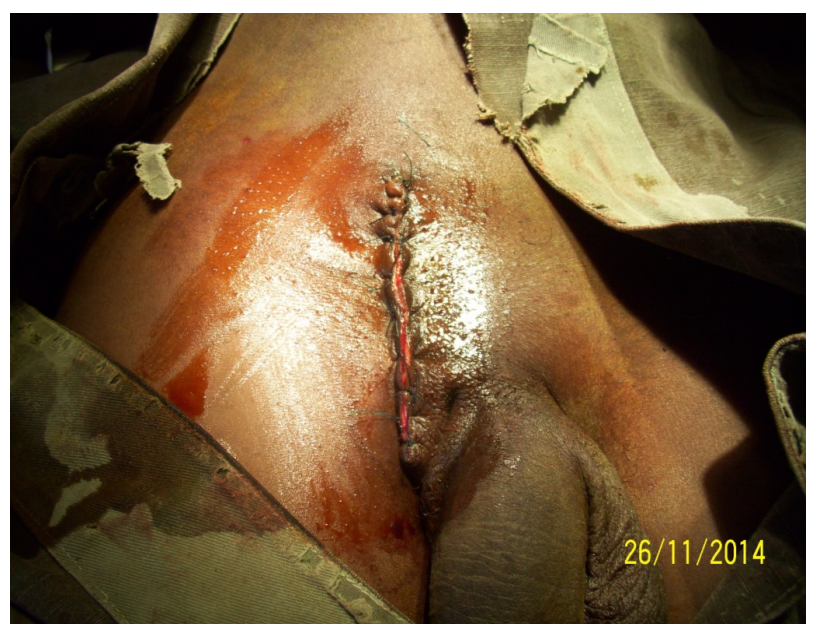

Figure 5. Final look.

The diagnosis is clinical and generally easy in the presence of pubopenial swelling with an empty, hypoplastic homolateral bursa [7]. A case of antenatal diagnosis at 38 weeks of amenorrhea has been reported by Mazneikova [8]. Real-time ultrasound associated with colour Doppler may have prognostic value, detecting areas of trauma and exploring testicular vascularization [4].

Treatment is surgical, indicated as soon as the diagnosis is made, regardless of age [1], due to the significant risk of microtrauma. It consists in reintegrating the testicle into the scrotal compartment, by the inguinal route in children, so it is an orchidectomy in the elderly subject because of the risk of malignant degeneration.

The long-term prognosis of pubopenian testicular ectopias is, for some authors, good due to the discretion of histological lesions [1]. Hutcheson, on the other hand, in a comparative study, did not find any significant difference between the histological lesions observed in cryptorchidism and those found in testicular ectopias including perineal locations. According to this author, it is a variant of the same congenital anomaly with a similar long-term prognosis [9]. 


\section{Conclusion}

Often easily diagnosed, pubopenic testicular ectopy remains a rare congenital anomaly. The functional prognosis, which is always difficult to specify, seems identical to the other locations.

\section{Conflicts of Interest}

The authors declare no conflicts of interest regarding the publication of this paper.

\section{References}

[1] Garat, J.M., Crisponi, H., Apostolo, C. and Etcheverry, A. (1985) Perineal Ectopic Testicle. Journal of Urology, 91, 469-472.

[2] Merrot, T. (2009) Prise en charge des testicules non descendusTreatment of undescended testicles. Progrès en Urologie, 19, 265-268.

https://doi.org/10.1016/j.purol.2008.10.028

[3] Carpenter, P.J. and Potter, E.L. (1959) Nuclear Sex and Genital Malformation in 48 Cases of Renal Agenesis, with Especial Reference to Nonspecific Female Pseudohermaphroditism. American Journal of Obstetrics \& Gynecology, 78, 235-258. https://doi.org/10.1016/0002-9378(59)90168-1

[4] Stroup, N.E., Edmonds, L. and O’Brien, T.R. (1990) Renal Agenesis and Dysgenesis: Are They Increasing? Teratology, 42, 383-395. https://doi.org/10.1002/tera.1420420407

[5] Argueso, L.R., Ritchey, M.L., Boyle Jr., E.T., Milliner, D.S., Bergstralh, E.J. and Kramer, A.G. (1992) Prognosis of Patients with Unilateral Renal Agenesis. Pediatric Nephrology, 6, 412-416. https://doi.org/10.1007/BF00873996

[6] Hutson, J.M., Terada, M., Zhou, B. and Williams, M.P.L. (1995) Normal Testicular Descent and the Aetiology of Cryptorchidism. Advances in Anatomy, Embryology and Cell Biology Vol. 132, Springer, Berlin, 1-56.

[7] Middleton, G.W., Beamon, C.R. and Gillenwater, J.Y. (1976) Two Rare Cases of Ectopic Testis. Journal of Urology, 115, 455-458. https://doi.org/10.1016/S0022-5347(17)59241-1

[8] Mazneikova, V. and Markov, D. (2001) Antenatal Ultrasound Diagnosis of Perineal Ectopic Testis: A Case Report. European Journal of UItrasound, 13, 31-33. https://doi.org/10.1016/S0929-8266(00)00121-X

[9] Schultz, D.J., Canning, D.A. and Huff, D.S. (2000) Ectopic and Undescended Testis: Variants of a Single Congenital Anomaly? Journal of Urology, 163, 961-963. https://doi.org/10.1016/S0022-5347(05)67864-0 